\title{
Response to: 'Comment on: Pressure and velocity in intraocular and subarachnoid space fluid chambers: an inseparable couple'
}

\author{
Hanspeter E. Killer ${ }^{1,2}$ - Achmed Pircher ${ }^{1,3}$ \\ Received: 16 April 2019 / Accepted: 16 April 2019 / Published online: 14 June 2019 \\ (C) The Royal College of Ophthalmologists 2019
}

To the Editor

We appreciate the thoughtful letter [1] by Dr. Harvey concerning our paper Pressure and velocity - an inseparable couple [2], which might have caused some confusion that we would like to clarify.

Dr. Harvey's concerns are focused exclusively on the situation in the anterior chamber of the eye in glaucoma, whereas we first considered cerebrospinal fluid (CSF) in the subarachnoid space of the optic nerve. We then added the behaviour of aqueous humour in the anterior chamber as a partial analogy to the CSF in the subarachnoid space (SAS). In his letter Dr. Harvey mentions the term "flow rate" (volume per time: $Q=V / t$ ), a term we never addressed in our paper.

The comments of Dr. Harvey may, however, help to clarify matters that have troubled other readers.

The subarachnoid space of the optic nerve is connected to the intracranial CSF spaces via the optic canal. CSF flows into the SAS from the pituitary cistern. This outflow pathway is not yet fully understood, but includes a lymphatic pathway in the dura of the optic nerve sheath [3].

While the inflow pathway consists of one route (via the optic canal), the outflow pathway may probably consist of a series of lymphatic clefts (and probably lymphatic pathways) [4] and maybe a reversed flow of fluid back to the optic canal. However, these structures can be considered as one outflow route (consisting of multiple small entities). In patients with elevated intracranial pressure, the diameter of

Hanspeter E. Killer

profesrielkiller@gmail.com

1 Department of Ophthalmology, Kantonsspital Aarau, Aarau, Switzerland

2 Department of Ophthalmology, University Hospital Basel, Basel, Switzerland

3 Department of Neuroscience/Ophthalmology, Uppsala University, Uppsala, Sweden the optic nerve sheath increases due to elevated pressure that is accompanied by lower velocity.

The relationship of pressure and velocity still works in the CSF space surrounding the optic nerve. We then theorised about the fluid dynamics in the anterior chamber in glaucoma.

We agree with Harvey as he rightly states: it is true that in an idealised single-fluid compartment described by the Bernoulli equation, if there is a steady flow, a raised IOP will be accompanied by a reduction in velocity. Full stop. However, this is what we described in our paper as shown in the figure on page 2 . We did not claim to have created a fluid model of the eye and the anterior chamber. We simplified the anatomy in an analogy of the subarachnoid space, and we are aware that the anatomical situation of the eye is of course more complex. This however does not invalidate the model in its principal conception.

Just as in the subarachnoid space, in the anterior chamber, there is one inflow route of aqueous humour from the ciliary body and basically one outflow route via Schlemm's canal and the uveoscleral pathway [5]. Although the outflow resistance in these two pathways may differ, they can function as one route. Of course, the aqueous flow varies with intraocular pressure as shown in the Goldman formula. However, a higher intraocular pressure (as in glaucoma) is not expected to increase outflow in a linear fashion. If this were the case, intraocular pressure would indeed not be a problem in glaucoma. That is why we lower the intraocular pressure in glaucoma with eyedrops or surgical techniques. Untreated intraocular pressure just levels on a higher scale — and the couple remains loyal although — of coursenot in a linear fashion.

We did not, as Dr. Harvey suggested, "erroneously" attribute a change in aqueous velocity as a primary mechanism of the pathophysiology of glaucoma, but described fluid behaviour in fluid compartments. Glaucoma is a disease with many components and pathomechanisms. Stagnation of aqueous humour might be one of them.

Prof. Habil, Dr. H.E. Killer and Dr. A. Pircher for the group. 


\section{Compliance with ethical standards}

Conflict of interest The authors declare that they have no conflict of interest.

Publisher's note: Springer Nature remains neutral with regard to jurisdictional claims in published maps and institutional affiliations.

\section{References}

1. Harvey JP. Comment on: Pressure and velocity in intraocular and subarachnoid space fluid chambers: an inseparable couple. Eye. 2019; https://doi.org/10.1038/s41433-019-0487-y. [Epub ahead of print].
2. Killer HE, Hou R, Wostyn P, Meyer P, Pircher A. Pressure and velocity in intraocularand subarachnoid space fluid chambers: an inseparable couple. Eye. 2019;33:343-6.

3. Killer HE, Laeng HR, Groscurth P. Lymphatic capillaries in the meninges oft he human optic nerve. J Neuroophthalmol. 1999;19: 1365-72.

4. Mathieu E, Gupta N, Ahari A, et al. Evidence for cerebrospinal fluid entry into the optic nerve via a glymphatic pathway. Invest Ophthalmol Vis Sci. 2017;58:4784-91.

5. Carreon $\mathrm{T}$, van der Merwe $\mathrm{E}$, Fellman RL, Johnstone $\mathrm{M}$, Bhattacharya SK. Aqueous outflow-a continuum from trabecular meshwork to episcleral veins. Prog Retin Eye Res. 2017;57:108-33. 